\title{
Enumerating the Preconditions of Agent Message Types
}

\author{
Francis Jeffry Pelletier and Renée Elio \\ Dept. Computing Science, Univ. Alberta \\ Edmonton, Alberta T6G 2H1 \\ $\{$ jeffp, ree\} @cs.ualberta.ca \\ http: //www.cs.ualberta.ca/ \{ jeffp, ree $\}$
}

\begin{abstract}
Agent communication languages (ACLs) invoke speech act theory and define individual message types by reference to particular combinations of beliefs and desires of the speaker (feasibility preconditions). Even when the mental states are restricted to a small set of nested beliefs, it seems that there might be a very large number of different possible preconditions, and therefore a very large number of different message types. With some constraints on the mental attitude of the speaker, we enumerate the possible belief states that could serve as preconditions for individual message types, and we identify how these states correspond to different possible message types. We then compare these with FIPA's primitive message types. Our approach clarifies the nature of core message types in an ACL, and perhaps settles issues concerning just how many, and what types of, speech acts should be seen as primitive in such languages.
\end{abstract}

\section{Introduction and Background}

We are interested in the question of how many distinct communicative actions can be taken by an agent when communicating using an agent communication language (ACL). The sorts of actions under consideration are speech acts, and the general background for this, in the context of our investigation, is provided by FIPA's "Agent Communicative Act Library Specification" [7]. Communicative acts are a subset of the different possible actions that agents might perform. We restrict our attention to them because they seem to be a simple subset of the whole array of possible actions. We hope that the method suggested for communicative acts might carry over to other actions also.

\subsection{Individuating Speech Acts}

The notion of a speech act was introduced by Austin [1] and developed by both the philosophical community, especially by Searle $[12,13]$, and the linguistic community, as for example by Sadock [11] and the contributors to [6]. This general conception was adopted 
by the AI "agent paradigm" that started in the early 1990s with DARPA's development of KQML [9], and has been carried over to FIPA's ACL. Key figures in this latter development have been Cohen \& Levesque, Sadek, and Singh (e.g., [4], [10], [14]), see [8] for a survey. All of these later writers acknowledge their debt to Searle's [13] general account.

Austin's [1] initial descriptions of speech acts included such leading examples as saying "I hereby pronounce you man and wife" or "I order you to remain quiet," and thereby making the people become married, or making someone be under an obligation to be quiet. In these cases the speaker needs to hold a certain socially-defined position, the audience needs to be in a certain relationship to the speaker and (sometimes) to each other, and the specific form of words uttered has to be of a certain type, etc. If all these were the case, then the utterance would have a certain conventional effect-the people would be married, the subject would have been ordered, and so on. Searle [12] focused on cases like "I promise you that I will repay the loan," where the speaker has to have certain intentions and beliefs - such as believing that there is a loan, that the hearer wants the loan repaid, that the hearer will understand the utterance to place the speaker under an obligation, and so on. If all these were fulfilled, then the utterance of this sentence (or any other one that had the same speaker-intentions) would be a promise, that is, it would be the placing of the speaker under an obligation.

Austin thought that by varying the social relationships, the beliefs of the speaker or audience, or the specific forms of words used, he could account for all the different (conventionally recognized) speech acts there were. He had divided them into five major groupings, and found very many subtypes within each grouping. Famously, he estimated there to be "the third order of ten" different speech acts.

Since Austin and Searle, there has been much debate both in Linguistics and in Philosophy over the matter of how many speech acts there are. And this same issue has arisen, often implicitly, in the agent communication literature. We view ourselves as continuing this discussion, but employing a different methodology.

\subsection{Individuating Speech Acts: The Role of Preconditions}

It might seem that since there are an infinite number of different things that can be said, there must be an infinite number of different possible communicative acts. But the idea is to ask for the number of different types of things that can be said, and these are what are to be called "speech acts". Examples of speech acts are informing, requesting, ordering, and the like. If $p$ and $q$ are different, then there is a sense in which inform-that- $p$ and informthat- $q$ are different; but there is also a sense where it is the same speech act that is directed at different "propositional contents." It is this latter sense, where these are the same speech act but with differing propositional contents, that we are interested in characterizing.

On the other hand, one can inform-that-p, request-that-p, order-that- $p$, and so on. These are each to be considered a different speech act, all directed to the same propositional content, $p$. It is also this sense, where these are different speech acts with the same proposi- 
tional content, that we are interested in characterizing: How many different speech acts (i.e., different types of communicative acts) are possible for a given propositional content?

Austin used many different types of information when he came to "individuating" speech acts: they might differ in the circumstances and persons involved, differ in the sorts of conventions involved, differ in the mental state of the speaker, and finally they might differ in the resulting mental state of the hearer. Any of these might vary while the others stay constant, and the result could be a different speech act. In theory this would suggest there could be literally an infinite number of different possible speech acts, and it is just an accident of English and modern civilization that we only happen to have "the third power of ten" that are in actual use and codified in our language.

Searle on the other hand defined the various speech acts that happened to be already codified in the language as being "constituted" by two classes of conditions: preparatory conditions and sincerity conditions. The preparatory conditions described conditions of the world that need to happen in order for the speaker to correctly attempt that speech act, such as being in a "socially superior condition" in order to correctly attempt to give an order. The sincerity conditions distinguished "merely apparent" instances of a speech act from genuine ones, for example would distinguish a lie from a genuine case of informing.

The idea that speech acts were individuated by social convention (Austin) or were "constituted by" their preparatory and sincerity conditions (Searle) was not agreed to by all philosophers and linguists (e.g., not by the influential [2]). However, the current ACL design specifications (including FIPA's) do continue a general characterization of the difference between two distinct speech acts as a matter of the "preconditions" that are relevant to each. For instance, to (genuinely) request that another agent perform some action, the speaker (requestor) can't believe that the other agent would do the action anyway. An agent can't perform a (genuine) act of confirming- $p$ if he doesn't believe $\mathrm{p}$, and also if he doesn't believe that the hearer is uncertain about p. And so on. Thus, the difference between types of communicative acts becomes a matter of there being a difference in these "feasibility preconditions" (FPs), as they are called by FIPA.

Searle also held that a sincere and non-defective speech act would require that the hearer in fact fulfill some conditions. (For instance, in order for an utterance to be a promise, the hearer in fact had to desire the future action of the speaker). Although FIPA does not have promise speech acts, nor any commissive speech acts, if it were to add such an act, its version of a promise would have the FP that the speaker believe that the hearer desire the future action; but it would not require that the hearer in fact desire it. This is because the speaker is thought to engage in its communicative acts only on account of its own, directly inspectable, mental attitudes.

It might be thought, once again, that since there are an infinite number of mental attitudes that a speaker might have, there are an infinite number of FPs that could be involved even when we are restricting our attention to one propositional content, $p$. For example, it might be thought that "speaker believes that $p$ but desires that $q$ " could be a FP for inform-that-p-while-desiring-that-q. And if this is allowed, then it would be a different 
speech act than inform-that-p-while-desiring-that-r, and so on. In this paper we restrict our attention to the case where the FPs involved with a speech act only admit the same propositional content as the main speech act. Thus in the speech acts that have $p$ as their propositional content, all the FPs will have speaker and hearer attitudes about $p$, and not about other propositions. In this we are following the majority of FIPA's speech act descriptions, although for some of their non-primitive speech acts they allow further modifications of the propositional content-such as complex actions that are "based on" $p$. Given that there are only a finite number of such further modifications, the considerations given below and our general method could be adapted to deal with them also; but for simplicity we will consider only the basic case where FPs are direct mental attitudes of the speaker and hearer about $p$ and about each other's attitudes toward $p$.

\subsection{Individuating Speech Acts: The Role of Effects}

Speech acts can also be characterized by their intended effects, as can be seen from the statements made by Austin and Searle. Austin thought that speech acts required a communal convention that both the speaker and the hearer needed to be a conscious part of, and the hearer needed to have "uptake" of the speaker's desire to participate in the convention, in order that an utterance by the speaker should count as a speech act. Searle considered that a hearer would in fact have to believe that the speaker is under an obligation in order for a speech act to be a promise.

In FIPA's ACL specification, these are called "rational effects." The rational effect of an inform- $p$ might be that the receiving agent now believes the propositional content of the inform. The rational effect of a promise might be that the hearer believe that the speaker is under an obligation. In FIPA's view, however, rational effects are not, strictly speaking, postconditions, because they are not guaranteed (messages may be lost; the mental state of the receiving agent is not in the control of the speaker, and in any case the hearer's mental response is generally unobservable to the sending agent). Thus speech acts are not even partially individuated by their rational effects. More generally, speech acts are a special case of an agent operating in a nondeterministic, partially observable environment over which it has only an indirect control, namely the mental state of another agent. And all an agent has to guide its actions are its own beliefs, desires, goals, and intentions concerning "external reality" (which includes other agents).

As a consequence, the rational effects of a speech act cannot be used to individuate one from another, since they are outside the speaker's control. To conclude: speech acts apparently cannot be individuated by their effects, but only by their preconditions.

\subsection{Planning a Speech Act}

The theory of an agent communicating crucially depends on being able to determine what FPs are currently satisfied. The general picture (due historically to [5], see [3] for discus- 
sion) is this. An agent desires to have the environment have a certain feature. (This desire is not necessarily a part of the communication process...it may have come about through other means such as being a feature of its design or being ordered by some outside agency. The feature might be as ephemeral as that another agent come to believe $p$.) The agent scans the various speech acts that are within its repertoire, finds one with the correct rational effect, then determines whether the FPs are satisfied. If they are, the agent performs that speech act. If not, then the agent might look to other speech acts to see if they have the desired rational effect, or it may set about the task to make the FPs become true. This picture of a dialog makes success be a matter of planning (in the classical AI sense); and as part of that plan it is required that a stash of speech acts with their associated FPs be accessible. For this reason it is necessary that we be able to give a clear accounting of what the range of possible FPs is.

\section{The Semantics of FPs}

Our strategy is going to be to investigate speech acts by inquiring into the class of possible FPs of speech acts. So we turn to a quick look at how FPs are given by FIPA.

\subsection{The Semantic Language}

The communicative acts offered by FIPA are assigned a semantics by means of statements in a Semantic Language (SL). Each speech act is associated with a formula of SL that describes the speech act; the speech act's FPs and rational effects are also given as formulas of SL. These SL statements are themselves interpreted in a possible worlds framework. The SL language is multi-modal, having belief, desire, uncertainty, and intend operators $\left(\mathrm{B}_{\mathrm{i}} \phi\right.$ means that agent $i$ believes that $\phi ; \mathrm{D}_{\mathrm{i}} \phi$ means that $i$ desires $\phi ; \mathrm{U}_{\mathrm{i}} \phi$ means that $i$ is uncertain about $\phi$ but thinks it more likely than $\neg \phi, \mathrm{I}_{i} \phi$ means that $i$ intends $\phi$ ). The $\mathrm{B}$ operator, which is what we will mainly be concerned with in this paper, is described as a KD45 modal operator. ${ }^{1}$ We shall not dwell in the details of such a logic (which is basically the $\mathrm{S}_{5}$ logic, except that the T-axiom, $\square \phi \Rightarrow \phi$, is replaced by the D-axiom, $\square \phi \Rightarrow \neg \square \neg \phi)$. Instead we mention here some "Rules" about KD45 that we will use in what follows.

\footnotetext{
${ }^{1}$ The $\mathrm{D}$ and I operators are described as KD logics. The U operator seems to be left formally undefined. It is not clear that it is even a normal $\mathrm{K}$ operator, since it is unclear that $\mathrm{U}_{\mathrm{i}} \phi$ and $\mathrm{U}_{\mathrm{i}} \psi$ would imply $\mathrm{U}_{\mathrm{i}}(\phi \& \psi)$; and this "aggregation" of a modal operator over \& is true in all Kripke-normal modal logics. Consider: if $\phi$ is .7 likely and $\psi$ is .6 likely and they're independent, isn't $(\phi \& \psi) .42$ likely? (We won't pursue this issue in the present paper).
} 
1. Self-contradictions inside the scope of one agent's B operator are contradictory: $\mathrm{B}_{\mathrm{i}}(\phi \& \neg \phi)$ is never true.

2. Beliefs of an agent cannot be contradictory: $\mathrm{B}_{\mathrm{i}} \phi$ and $\mathrm{B}_{\mathrm{i}} \neg \phi$ are never jointly satisfiable. (So in particular, $\mathrm{B}_{\mathrm{i}} \phi$ implies $\neg \mathrm{B}_{\mathrm{i}} \neg \phi$ ).

3 . If an agent believes $\phi$, then the agent believes the logical consequences of $\phi$. (A special case is that an agent believes all tautologies).

4. Believing $p$ is equivalent to believing that you believe it: $\mathrm{B}_{\mathrm{i}} \phi$ is equivalent to $\mathrm{B}_{\mathrm{i}} \mathrm{B}_{\mathrm{i}} \phi$.

5. Not believing $p$ is equivalent to believing that you don't believe it: $\neg B_{i} \phi$ is equivalent to $\mathrm{B}_{\mathrm{i}} \neg \mathrm{B}_{\mathrm{i}} \phi$.

6. Although for a given proposition $p$, an agent might believe neither of $p$ and $\neg p$, it is required that the agent not believe either $p$ or $\neg p$ : $\left[\neg \mathrm{B}_{\mathrm{i}} \neg \mathrm{p} \vee \neg \mathrm{B}_{\mathrm{i}} \mathrm{p}\right]$ is necessarily true.

7. If all the propositional variables in $\phi$ are each in the scope of a $\mathrm{B}_{\mathrm{i}}$-operator (not necessarily the same one), then $\phi$ is equivalent to $\mathrm{B}_{\mathrm{i}} \phi$.

\subsection{FIPA's Primitive Message Types}

FIPA gives four primitive message types, which we state here, using a slightly different formalism than FIPA does by expanding their abbreviations.

1. $<\mathrm{i}, \operatorname{inform}(\mathrm{h}, \phi)>$

FP: $\mathrm{B}_{\mathrm{i}} \phi$ $\neg \mathrm{B}_{\mathrm{i}}\left[\mathrm{B}_{\mathrm{h}} \phi \vee \mathrm{B}_{\mathrm{h}} \neg \phi \vee \mathrm{U}_{\mathrm{h}} \phi \vee \mathrm{U}_{\mathrm{h}} \neg \phi\right]$

$\mathrm{RE}: \mathrm{B}_{\mathrm{h}} \phi$

2. $<\mathrm{i}$, confirm $(\mathrm{h}, \phi)>$
FP: $\mathrm{B}_{\mathrm{i}} \phi$
$\mathrm{B}_{\mathrm{i}} \mathrm{U}_{\mathrm{h}} \phi$
RE: $B_{h} \phi$

3. $<\mathrm{i}, \operatorname{disconfirm}(\mathrm{h}, \phi)>$

FP: $\quad B_{i} \neg \phi$

RE: $\quad \mathrm{B}_{\mathrm{h}} \neg \phi$

4. $<\mathrm{i}$, request $(\mathrm{h}, \alpha)>$

FP: $\quad \operatorname{FP}(\alpha)[i \backslash h]$

$\mathrm{B}_{\mathrm{i}} \operatorname{Agent}(\mathrm{h}, \alpha)$

$\neg \mathrm{B}_{\mathrm{i}} \mathrm{I}_{\mathrm{h}}$ Done $(\alpha)$

RE: $\quad \operatorname{Done}(\alpha)$

The request message type is more complicated than the others because it involves requesting the hearer to do an action $\alpha$; and this involves issues concerning whether the requestor believes the hearer intends to do $\alpha$ anyway, and whether those parts of the FPs of $\alpha$ that are mental attitudes of $i$ are satisfied, and so on. The more straightforward ones are the other three. An agent can inform a hearer of something if the agent believes it and believes the hearer does not believe it or its negation nor is uncertain of it or its negation. It can confirm something if it believes it and also believes the hearer is uncertain of it; it can disconfirm something if it disbelieves it but believes the hearer either believes it or is uncertain of it. We will contrast these primitive types with some further ones that we describe later. 


\section{Characterizing Feasibility Preconditions}

We are interested in determining how many communicative acts there are by investigating the space of possible FPs for speech acts. Another way of putting our basic question is: How many different configurations of an agent's mental state might there be in a KD45 logic, concerning proposition $p$ and a hearer, that in turn might be employed as feasibility preconditions for speech acts? Our aim is to specify a "grammar" that will exhaustively list the FPs that can be stated in the Semantic Language.

To make this question simpler, we will consider only what FIPA calls "primitive communicative acts." Non-primitive acts relevant to the propositional content $p$ might turn out to "expand" on $p$, and therefore not be just concerning $p$ simply. For instance, the non-primitive communicative act query-if $(i, j, \phi)$ means that agent $i$ is requesting agent $j$ to inform it of the truth of $\phi$. This non-primitive speech act is defined in terms of request and inform; the FPs for this act mention more than just $i, j$ and the content of $\phi$.

So, we wish to consider how many primitive speech acts there can be that involve propositional content $p$, by considering how many different FPs there can be that mention only $p$ as their propositional content and the beliefs of $i$ and $h$, the speaker and hearer (respectively) of the speech act. The characterization of FPs in FIPA is not well-defined, but one can glean certain features from their examples. We will start with some of the simpler features and try to decide how many different FPs there can be using only these simple features. Then we will briefly talk about more complex ways of constructing FPs.

\subsection{FP-sets}

First, we will define a FP-set to be a set of individual formulas, each one of which is a legitimate feasibility formula (which we call an FF). FIPA sometimes uses conjunction to conjoin these FFs and thereby make an FP just be one conjunctive formula; but sometimes it allows for there to be two or more different FFs and then the FP is that group of FFs...understood as their all being satisfied. We are approaching it in the latter way: we will give a number of simple formulas that are individual feasibility formulas, and will consider the FP-set to be a group of these FFs, and we will make sure that none of the individual formulas is itself a conjunction.

As we remarked before, FIPA allows not only the propositional content to play a role in individual FFs, but allows the speaker agent to have various mental attitudes towards this propositional content, such as believing it or being uncertain about it or desiring it, and the like. And it allows the speaking agent to have beliefs (etc.) about the beliefs (etc.) of the hearing agent. And so forth.

Although this sounds like it can lead to an infinite number of different FFs (agent $i$ believes that agent $j$ doesn't believe that agent $i$ desires.....), in fact the examples suggest 
that FIPA keeps a tight limit on the amount of such iteration. ${ }^{2}$ We will here give a very simple grammar designed only to accommodate the speaking agent $(i)$, the hearing agent $(h)$, the propositional content $(p)$, and their beliefs (represented as B, with a subscript determining which agent has the belief). The FIPA examples allow negations and disjunctions, also. But again, they are limited and not allowed to generate an infinite number of FFs (at least, not in their examples). There is always uncertainty in trying to induce a general claim on the basis of limited examples, and our attempt to give regularity in the form of a grammar to FIPAs examples might result in something FIPA would reject. We would ask them to provide the specific grammar of allowable FFs so that we can more confidently apply our method.

We can begin by specifying a formal grammar of FFs for agents $i$ and $h$, and propositional content $p$ (letting $\alpha$ be a variable taking values of either $i$ for speaker or $h$ for hearer). In our initial analysis, we will be concerned only with a single modal operator, B. (That is, we will ignore for this document mental attitudes towards complex propositions, which themselves might be about mental attitudes, e.g., I believe you know that I desire that you know that I don't know p). The disjunctive possibilities we enumerate are in some of FIPA's examples.

\section{BNF rule}

1. $<$ simple-statement $>:=\mathrm{p} \mid \neg \mathrm{p}$

2. $<$ simple-attitude $>:=\quad \mathrm{B}_{\alpha}<$ simple-statement $>$ I $\neg \mathrm{B}_{\alpha}<$ simple-statement $>$

3. $<$ cmpd-attitude $>:=[<$ simple-attitude $>\vee<$ simple-attitude $>]$

4. $<$ attitude $>$ :=

$$
\begin{gathered}
\mathrm{B}_{\mathrm{i}}<\text { simple-statement }>\text { | } \\
\mathrm{B}_{\mathrm{i}}<\text { simple-attitude }>\text { | } \\
\neg \mathrm{B}_{\mathrm{i}}<\text { simple-attitude }>1 \\
\mathrm{~B}_{\mathrm{i}}<\text { cmpd-attitude }>\text { | } \\
\neg \mathrm{B}_{\mathrm{i}}<\text { cmpd-attitude }>
\end{gathered}
$$

\section{Examples of generated formulas}

$$
\begin{gathered}
\mathrm{B}_{\alpha} \mathrm{p}, \quad \mathrm{B}_{\alpha} \neg \mathrm{p} \\
\neg \mathrm{B}_{\alpha} \mathrm{p}, \quad \neg \mathrm{B}_{\alpha} \neg \mathrm{p} \\
{\left[\mathrm{B}_{\alpha} \mathrm{p} \vee \mathrm{B}_{\alpha} \neg \mathrm{p}\right]} \\
\\
\mathrm{B}_{\mathrm{i}} \mathrm{p}, \quad \neg \mathrm{B}_{\mathrm{i}} \mathrm{p} \ldots \ldots \\
\mathrm{B}_{\mathrm{i}} \mathrm{B}_{\alpha} \neg \mathrm{p} \\
\neg \mathrm{B}_{\mathrm{i}} \neg \mathrm{B}{ }_{\alpha} \mathrm{p} \\
\mathrm{B}_{\mathrm{i}}\left[\mathrm{B}_{\alpha} \mathrm{p} \vee \mathrm{B}_{\alpha} \neg \mathrm{p}\right] \\
\neg \mathrm{B}_{\mathrm{i}}\left[\mathrm{B}_{\alpha} \mathrm{p} \vee \mathrm{B}_{\alpha} \neg \mathrm{p}\right]
\end{gathered}
$$

\footnotetext{
2 The FIPA document [7] uses the sort of examples of FFs we are characterizing here, calling it "the operational semantics". But in footnotes it also gives a "theoretical semantics" for the FFs. The main difference, perhaps the only difference, is that the B operator is replaced by MB, standing for "mutual belief" - the infinitely iterated " $i$ believes that $h$ believes that $i$ believes that..." Our grammar described below could also generate such statements by replacing the B operator with an MB operator, but we will instead follow the examples used in the operational semantics for simplicity of explanation.
} 
The <attitude> strings allowed by this grammar each describe a mental activity of an agent, and any subset of these strings then constitutes a mental state of an agent, using only the Belief operator. Any such string subset is a candidate for use as a feasibility precondition of a speech act. Hence, an FP-set is a (non-empty) set of <attitude> FF's.

\subsection{Some Semantic Restrictions on FP-sets}

There are various semantic constraints that exclude many of the sets that can be produced with this grammar. No such set is allowed to be contradictory for example, so no FP-set can contain both an <attitude> and its corresponding negation. (However, it might contain neither, as when the feasibility preconditions for some communicative act do not require that the speaker have any opinions about $p$-as for example the preconditions for query-if in FIPA's specifications).

Furthermore, being a KD45 operator imposes some other requirements on the FP-sets, such as that there can be no case of $\mathrm{B}_{\mathrm{i}} \mathrm{q}$ and $\left.\mathrm{B}_{\mathrm{i}}\right\urcorner \mathrm{q}$ (for any $q$ ), as noted above in Rule 2 . Rule 5 requires that $\mathrm{B}_{i} q$ and $\mathrm{B}_{\mathrm{i}} \mathrm{B}_{\mathrm{i}} \mathrm{q}$ are the same, and therefore (a) if one FF has the former as a subpart where another FF has the latter and that is their only difference, then they are the same FF, and so (b) if one FP has one of these formulas while the other FP has both formulas, and there is no other difference, then they are the same FP. Using the same Rule, since $\mathrm{B}_{i} q$ and $\mathrm{B}_{i} \mathrm{~B}_{i} q$ are the same, if an FP has $\mathrm{B}_{i} q$ and also $\neg \mathrm{B}_{i} \mathrm{~B}_{i} q$ [or the reverse negations], then this is an impossible FP. (The same holds for the beliefs of $j$ ).

More generally speaking, Rule 7 says that if the main operator of each of $X$ and $Y$ is $B_{i}$ (for example, maybe $X$ is the formula $B_{i}\left(B_{j} p \vee \neg p\right)$ and $Y$ is the formula $B_{i}\left(q \vee \neg B_{j} p\right)-$ both $X$ and $Y$ have $B_{i}$ as a main operator), then $B_{i}(X \vee Y)$ is the same as $(X \vee Y)$. In other words, the addition of a $\mathrm{B}_{\mathrm{i}}$ to a formula that already has all sentence letters in the scope of a $\mathrm{B}_{\mathrm{i}}$ does not yield a semantically different formula. (The same holds for the beliefs of $h$ ).

We modified the above grammar so that it incorporated some of the constraints mentioned above. The resulting grammar generated these sentences, plus their negations:

\begin{tabular}{|c|c|c|}
\hline$B_{i} p$ & $\mathrm{~B}_{\mathrm{i}} \neg \mathrm{p}$ & $\mathrm{B}_{\mathrm{i}} \mathrm{B}_{\mathrm{h}} \mathrm{p}$ \\
\hline $\mathrm{B}_{\mathrm{i}} \neg \mathrm{B}_{\mathrm{h}} \mathrm{p}$ & $\mathrm{B}_{\mathrm{i}} \mathrm{B}_{\mathrm{h}} \neg \mathrm{p}$ & $\mathrm{B}_{\mathrm{i}} \neg \mathrm{B}_{\mathrm{h}} \neg \mathrm{p}$ \\
\hline $\mathrm{B}_{\mathrm{i}}\left[\mathrm{B}_{\mathrm{h}} \mathrm{p} \vee \mathrm{B}_{\mathrm{h}} \mathrm{p}\right]$ & $\mathrm{B}_{\mathrm{i}}\left[\neg \mathrm{B}_{\mathrm{h}} \mathrm{p} \vee \mathrm{B}_{\mathrm{h}} \mathrm{p}\right]$ & $\mathrm{B}_{\mathrm{i}}\left[\mathrm{B}_{\mathrm{h}} \neg \mathrm{p} \vee \mathrm{B}_{\mathrm{h}} \mathrm{p}\right]$ \\
\hline $\mathrm{B}_{\mathrm{i}}\left[\neg \mathrm{B}_{\mathrm{h}} \neg \mathrm{p} \vee \mathrm{B}_{\mathrm{h}} \mathrm{p}\right]$ & $\mathrm{B}_{\mathrm{i}}\left[\mathrm{B}_{\mathrm{h}} \mathrm{p} \vee \neg \mathrm{B}_{\mathrm{h}} \mathrm{p}\right]$ & $\mathrm{B}_{\mathrm{i}}\left[\neg \mathrm{B}_{\mathrm{h}} \mathrm{p} \vee \neg \mathrm{B}_{\mathrm{h}} \mathrm{p}\right]$ \\
\hline $\mathrm{B}_{\mathrm{i}}\left[\mathrm{B}_{\mathrm{h}} \neg \mathrm{p} \vee \neg \mathrm{B}_{\mathrm{h}} \mathrm{p}\right]$ & $\mathrm{B}_{\mathrm{i}}\left[\neg \mathrm{B}_{\mathrm{h}} \neg \mathrm{p} \vee \neg \mathrm{B}_{\mathrm{h}} \mathrm{p}\right]$ & $\mathrm{B}_{\mathrm{i}}\left[\mathrm{B}_{\mathrm{h}} \mathrm{p} \vee \mathrm{B}_{\mathrm{h}} \neg \mathrm{p}\right]$ \\
\hline $\mathrm{B}_{\mathrm{i}}\left[\neg \mathrm{B}_{\mathrm{h}} \mathrm{p} \vee \mathrm{B}_{\mathrm{h}} \neg \mathrm{p}\right]$ & $\mathrm{B}_{\mathrm{i}}\left[\mathrm{B}_{\mathrm{h}} \neg \mathrm{p} \vee \mathrm{B}_{\mathrm{h}} \neg \mathrm{p}\right]$ & $\mathrm{B}_{\mathrm{i}}\left[\neg \mathrm{B}_{\mathrm{h}} \neg \mathrm{p} \vee \mathrm{B}_{\mathrm{h}} \neg \mathrm{p}\right]$ \\
\hline $\mathrm{B}_{\mathrm{i}}\left[\mathrm{B}_{\mathrm{h}} \mathrm{p} \vee \neg \mathrm{B}_{\mathrm{h}} \neg \mathrm{p}\right]$ & $\mathrm{B}_{\mathrm{i}}\left[\neg \mathrm{B}_{\mathrm{h}} \mathrm{p} \vee \neg \mathrm{B}_{\mathrm{h}} \neg \mathrm{p}\right]$ & $\mathrm{B}_{\mathrm{i}}\left[\mathrm{B}_{\mathrm{h}} \neg \mathrm{p} \vee \neg \mathrm{B}_{\mathrm{h}} \neg \mathrm{p}\right]$ \\
\hline
\end{tabular}

From these we remove "duplicates", that is, strings that merely have different syntactic orders of the components. This leaves us with the following 10, plus their negations (which we will discuss in Section 3.5); we divide them into three groupings: 


$\begin{array}{lll}\text { Group 1 } & \text { Group 2 } & \text { Group 3 } \\ \text { 1. } \mathrm{B}_{\mathrm{i}} \mathrm{p} & \text { 7. } \mathrm{B}_{\mathrm{i}}\left[\mathrm{B}_{\mathrm{h}} \neg \mathrm{p} \vee \mathrm{B}_{\mathrm{h}} \mathrm{p}\right] & \text { 8. } \mathrm{B}_{\mathrm{i}}\left[\neg \mathrm{B}_{\mathrm{h}} \neg \mathrm{p} \vee \mathrm{B}_{\mathrm{h}} \mathrm{p}\right] \\ \text { 2. } \mathrm{B}_{\mathrm{i}} \neg \mathrm{p} & & 9 . \mathrm{B}_{\mathrm{i}}\left[\mathrm{B}_{\mathrm{h}} \neg \mathrm{p} \vee \neg \mathrm{B}_{\mathrm{h}} \mathrm{p}\right] \\ \text { 3. } \mathrm{B}_{\mathrm{i}} \mathrm{B}_{\mathrm{h}} \mathrm{p} & & \\ \left.\text { 4. } \mathrm{B}_{\mathrm{i}} \mathrm{B}_{\mathrm{h}}\right\urcorner \mathrm{p} & & \\ \text { 5. } \mathrm{B}_{\mathrm{i}} \neg \mathrm{B}_{\mathrm{h}} \mathrm{p} & & \\ \text { 6. } \mathrm{B}_{\mathrm{i}} \neg \mathrm{B}_{\mathrm{h}} \neg \mathrm{p} & & \end{array}$

The embedded part of formula (7) expresses that the hearer has a definite belief about $p$, without stating what direction that belief takes. FIPA uses $\mathrm{Bif}_{h}(\mathrm{p})$ as an abbreviation for this concept, and so formula (7) could also have been stated as $\mathrm{B}_{\mathrm{i}} \mathrm{Bif}_{\mathrm{h}}(\mathrm{p})$. [Note also that $\operatorname{Bif}_{\alpha}(p)$ is equivalent to $\operatorname{Bif}_{\alpha}(\neg p)$.]

\subsection{Further Semantic Restrictions on FP-sets}

It turns out that the members of Group 3 are not independently interesting. In KD45, formula 8 is equivalent to formula $6,{ }^{3}$ and formula 9 is equivalent to formula $4 .{ }^{4}$ The embedded disjunction in formula 10 expresses a tautology, according to Rule 6 . Therefore agent $i$ must believe it, according to Rule 3, and thus 10 expresses no real requirement on FFs. We therefore have only the first seven formulas as FFs that can be used to form the feasibility preconditions for speech acts, at least when restricted as we have done to the propositional content of the speech act and the beliefs of the speaker. If it were true that any (non-empty) FP-set made up from these could determine a speech act, we would have $\left(2^{7}-1\right)=127$ different speech acts that could be defined from these formulas.

However, there are further relationships that hold in KD45 among the seven FFs. Obviously we cannot have both (1) and (2) in any FP-set, nor both (3) and (4), nor both (5) and (6). [Although for any of these pairs we might have neither in an FP-set.] It might also be noted that (3) implies (6), ${ }^{5}$ and also that (3) implies (7). ${ }^{6}$ (6) and (7) together

\footnotetext{
${ }^{3}$ Since $\neg \mathrm{B}_{\mathrm{h}} \neg \mathrm{p}$ implies $\left[\neg \mathrm{B}_{\mathrm{h}} \neg \mathrm{p} \vee \mathrm{B}_{\mathrm{h}} \mathrm{p}\right.$ ], it follows by Rule 3 that if $i$ believes the former then $i$ must believe the latter, so 6 implies 8 . For the other direction, note that each disjunct of $\left[\neg B_{h} \neg p \vee B_{h} p\right]$ implies $\neg B_{h} \neg p$, the former because of identity, the latter because of Rule 2 . Thus, if $i$ believes the disjunction, then by Rule 3, $i$ must believe $\neg \mathrm{B}_{\mathrm{h}} \neg \mathrm{p}$.

${ }^{4}$ As with the previous case, 6 obviously implies 9, by Rule 3. For the other direction, each disjunct of $\left[\mathrm{B}_{\mathrm{h}} \neg \mathrm{p} \vee \neg \mathrm{B}_{\mathrm{h}} \mathrm{p}\right]$ implies $\neg \mathrm{B}_{\mathrm{h}} \mathrm{p}$, and therefore since $i$ believes the disjunction $i$ must believe $\neg B_{h}$ p because of Rule 3 .

${ }^{5}$ By Rule 2, $\mathrm{B}_{\mathrm{h}} \mathrm{p}$ implies $\neg \mathrm{B}_{\mathrm{h}} \neg \mathrm{p}$, so since agent $i$ believes $\mathrm{B}_{\mathrm{h}} \mathrm{p}$, agent $i$ must also believe $\neg B_{h} \neg$ p, according to Rule 3. I.e., $B_{i} B_{h} p$ implies $B_{i} \neg B_{h} \neg p$.

${ }^{6}$ Since $B_{h} p$ implies $\left[B_{h} \neg p \vee B_{h} p\right], B_{i} B_{h} p$ must imply $B_{i}\left[B_{h} \neg p \vee B_{h} p\right]$ by Rule 3 .
} 
imply (3). ${ }^{7}$ This has various implications. Obvious ones are that any FP-set that has (3) must also include both (6) and (7), and any FP-set with both (6) and (7) must include also (3). At a somewhat deeper level of explanation, we might say that, since (3) is not really a separate FF from (6) and (7), we need to decide which is more fundamental: (3) itself, or the pair (6) and (7). To decide this, we need to determine whether there is an identifiable speech act that has (6) as a precondition but not (7)...or the reverse. If we decide this is not possible, then (6) and (7) should not count as separate FFs, but rather we should only use (3). If, on the other hand, we find there to be speech acts that have only one of them in their FP-set, then (3) should not count as a separate FF but instead we should allow (6) and (7) to occur separately sometimes, and sometimes together. And when they occur together that has the effect of adopting (3). We will not now dictate on this issue, but instead will present our analysis as two separate cases.

A similar situation holds among (4), (5), and a formula we have not yet considered,

$$
\text { 7*. } \quad \mathrm{B}_{\mathrm{i}} \neg\left[\mathrm{B}_{\mathrm{h}} \neg \mathrm{p} \vee \mathrm{B}_{\mathrm{h}} \mathrm{p}\right]
$$

This formula is not generated by our grammar for FFs, nor should it have been, because it is equivalent to $(7 * a)$, which in turn is equivalent to $(7 * b)$, in KD45

$$
\begin{array}{ll}
7^{*} \text { a. } & \mathrm{B}_{\mathrm{i}}\left[\neg \mathrm{B}_{\mathrm{h}} \neg \mathrm{p} \& \text { \& } \mathrm{B}_{\mathrm{h}} \mathrm{p}\right] \\
7^{*} \text { b. } & \mathrm{B}_{\mathrm{i}} \neg \mathrm{B}_{\mathrm{h}} \neg \mathrm{p} \& \mathrm{~B}_{\mathrm{i}} \neg \mathrm{B}_{\mathrm{h}} \mathrm{p}
\end{array}
$$

which can be seen to be just the conjunction of formulas (5) and (6)...and our grammar only generates the individual conjuncts instead of the conjunctions. (The conjunction is represented by putting both conjuncts into the same FP-set).

Formula (4) implies (5) and (7*) for the same reasons that (3) implies (6) and (7). And similarly, (5) and (7*) imply (4). As was the case with (3) and (6)/(7), we note that (4) is not a separate FF from (5) and ( $7 *)$, and so we need to decide whether to make (4) be a legitimate FF (and then (5) and ( $\left.7^{*}\right)$ wouldn't be), or whether to make (5) and $\left(7^{*}\right)$ be the primitive ones and (4) merely be implicit in the FP-sets that would have both. Recall that $\left(7^{*}\right)$ is really the conjunction of (5) and (6), and so the question becomes whether (5) and (6) can be pried apart from one another and appear in different speech acts.

Let us then give the two options: Option A treats (3) as the basic FF, thereby insisting that (6) and (7) cannot appear as basic FFs. Option B treats (6) and (7) as basic FFs, and (3) merely as a consequence that follows from other FFs in those FP-sets which happen to contain both (6) and (7). A similar state of affairs holds with the formulas (4) vs. (5) and (6). Note, however, that both (3) and (4) imply (6). This means that we need to treat the two states of affairs in the same way. That is, if we choose to treat (3) as a basic FF, we must do the same with (4); if we choose to treat (6) and (7) as basic, then we must also treat (5) and (6) as basic.

\footnotetext{
${ }^{7}$ Since $\neg \mathrm{B}_{\mathrm{h}} \neg \mathrm{p}$ and $\left[\mathrm{B}_{\mathrm{h}} \neg \mathrm{p} \vee \mathrm{B}_{\mathrm{h}} \mathrm{p}\right]$ together imply $\mathrm{B}_{\mathrm{h}} \mathrm{p}$, and since $i$ believes both of the former, $i$
} must also believe the latter, by Rule 3. I.e., (6) and (7) imply (3). 
Employing our seven formulas, in the two Options, the basic FFs are:

\section{Option A \\ 1. $\mathrm{B}_{\mathrm{i}} \mathrm{p}$ \\ 2. $\mathrm{B}_{\mathrm{i}} \neg \mathrm{p}$ \\ 3. $\mathrm{B}_{\mathrm{i}} \mathrm{B}_{\mathrm{h}} \mathrm{p}$ \\ 4. $\mathrm{B}_{\mathrm{i}} \mathrm{B}_{\mathrm{h}} \neg \mathrm{p}$}

\section{Option B}

1. $\mathrm{B}_{\mathrm{i}} \mathrm{p}$

2. $B_{i} \neg p$

5. $\left.\mathrm{B}_{\mathrm{i}}\right\urcorner \mathrm{B}_{\mathrm{h}} \mathrm{p}$

6. $B_{i} \neg B_{h} \neg p$

7. $\left.B_{\mathrm{i}}\left[\mathrm{B}_{\mathrm{h}}\right\urcorner \mathrm{p} \vee \mathrm{B}_{\mathrm{h}} \mathrm{p}\right]$

Any non-empty set of these is a FP-set. There are $\left(2^{4}-1\right)=15$ such sets in Option A, not all of which are legitimate (e.g., 1 and 2 can't appear in the same set). In Option B, there are $\left(2^{5}-1\right)=31$ FP-sets, not all of which are legitimate.

\subsection{FP-Sets}

Starting with Option A, we have already remarked that no FP-set can have both (1) and (2) in it, although it may have neither. No FP-set can have both (3) and (4) in it either, since agent $i$ cannot believe that agent $h$ believes both $p$ and $\neg p \ldots$ at least not in a KD45 system of belief. (Each agent is consistent, and each agent believes that each agent is consistent). Again, though, an FP-set may contain neither. Each of (1) and (2) is independent of each of (3) and (4). There are nine sets that contain (a) at most one of (1) and (2), and (b) at most one of (3) and (4). One of these nine sets is empty, so there are eight legitimate FPsets in Option A:

$$
\begin{array}{lll}
\text { FP-1(A): } & \left\{B_{i} p\right\} & \text { FP-5(A): }\left\{B_{i} p, B_{i} B_{h} p\right\} \\
\text { FP-2(A): } & \left.\left\{B_{i}\right\urcorner p\right\} & \text { FP-6(A): } \left.\left\{B_{i} p, B_{i} B_{h}\right\urcorner p\right\} \\
\text { FP-3(A): }\left\{B_{i} B_{h} p\right\} & \text { FP-7(A): }\left\{B_{i} \neg p, B_{i} B_{h} p\right\} \\
\text { FP-4(A): }\left\{B_{i} B_{h} \neg p\right\} & \text { FP-8(A): }\left\{B_{i} \neg p, B_{i} B_{h} \neg p\right\}
\end{array}
$$

In Option B, once again FFs (1) and (2) can't both occur in the same FP-set (but perhaps neither does). But at least one of FF (5) and (6) must occur, according to Rule 6. ${ }^{8}$ If both (5) and (6) are in an FP-set, then (7) cannot be in it. ${ }^{9}$ We therefore generate the following 15 legitimate FP-sets in Option B.

$$
\begin{aligned}
& \text { FP-1(B): } \quad\left\{B_{\mathrm{i}} \neg \mathrm{B}_{\mathrm{h}} \mathrm{p}\right\} \\
& \text { FP-2(B): } \quad\left\{B_{i} \neg B_{h} \neg p\right\} \\
& \text { FP-9(B): } \quad\left\{\mathrm{B}_{\mathrm{i}} \neg \mathrm{B}_{\mathrm{h}} \neg \mathrm{p}, \mathrm{B}_{\mathrm{i}}\left[\mathrm{B}_{\mathrm{h}} \neg \mathrm{p} \vee \mathrm{B}_{\mathrm{h}} \mathrm{p}\right]\right\} \\
& \text { FP-3(B): } \quad\left\{\mathrm{B}_{\mathrm{i}} \mathrm{p}, \mathrm{B}_{\mathrm{i}} \neg \mathrm{B}_{\mathrm{h}} \mathrm{p}\right\} \\
& \text { FP-10(B): } \left.\left.\left.\left\{\mathrm{B}_{\mathrm{i}} \mathrm{p}, \mathrm{B}_{\mathrm{i}}\right\urcorner \mathrm{B}_{\mathrm{h}} \mathrm{p}, \mathrm{B}_{\mathrm{i}}\right\urcorner \mathrm{B}_{\mathrm{h}}\right\urcorner \mathrm{p}\right\} \\
& \text { FP-4(B): }\left\{B_{i} p, B_{i} \neg B_{h} \neg p\right\} \\
& \text { FP-11(B): } \left.\left\{\mathrm{B}_{\mathrm{i}} \mathrm{p}, \mathrm{B}_{\mathrm{i}}\right\urcorner \mathrm{B}_{\mathrm{h}} \mathrm{p}, \mathrm{B}_{\mathrm{i}}\left[\mathrm{B}_{\mathrm{h}} \neg \mathrm{p} \vee \mathrm{B}_{\mathrm{h}} \mathrm{p}\right]\right\} \\
& \text { FP-12(B): } \left.\left\{B_{i} p, B_{i} \neg B_{h}\right\urcorner p, B_{i}\left[B_{h} \neg p \vee B_{h} p\right]\right\}
\end{aligned}
$$

\footnotetext{
${ }^{8}$ By Rule 6 , either $\neg B_{h} p$ or $\neg B_{h} \neg$ p. It follows by Rule 3 that either $B_{i} \neg B_{h} p$ or $B_{i} \neg B_{h} \neg p$.

${ }^{9}$ As we remarked above, (5) and (6) imply (7*). But (7) and (7*) attribute contradictory beliefs to agent $i$, and so (5) and (6) together Rule out (7).
} 


$$
\begin{aligned}
& \text { FP-5(B): } \left.\left\{B_{i} \neg p, B_{i}\right\urcorner B_{h} p\right\} \quad \text { FP-13(B): }\left\{B_{i} \neg p, B_{i} \neg B_{h} p, B_{i} \neg B_{h} \neg p\right\} \\
& \text { FP-6(B): } \left.\left.\quad\left\{B_{i}\right\urcorner p, B_{i} \neg B_{h} \neg p\right\} \quad \text { FP-14(B): }\left\{B_{i} \neg p, B_{i} \neg B_{h} p, B_{i}\left[B_{h}\right\urcorner p \vee B_{h} p\right]\right\} \\
& \text { FP-7(B): } \left.\left.\left.\left.\quad\left\{B_{i}\right\urcorner B_{h} p, B_{i} \neg B_{h}\right\urcorner p\right\} \quad \text { FP-15(B): }\left\{B_{i}\right\urcorner p, B_{i}\right\urcorner B_{h} \neg p, B_{i}\left[B_{h} \neg p \vee B_{h} p\right]\right\} \\
& \text { FP-8(B): } \left.\left.\quad\left\{B_{i}\right\urcorner B_{h} p, B_{i}\left[B_{h}\right\urcorner p \vee B_{h} p\right]\right\}
\end{aligned}
$$

\subsection{Negative Feasibility Formulas}

Although our grammar generated FFs that were negations of formulas expressing a belief of the speaker, we have not considered them so far. It might be thought that, since all feasibility conditions have to be truths about the mental states of the speaker, there could therefore be no FFs that did not have $B_{i}$ as its main operator... a FF that started $\neg B_{i}$ would be illegitimate, since it says that in fact agent $i$ does not believe such-and-so. Although this general reasoning is correct, in KD45 formulas of the form $\neg \mathrm{B}_{i} \phi$ are equivalent to $\mathrm{B} \neg \mathrm{B}_{i} \phi$, as we saw in Rule 5, and therefore they are legitimate FFs. ${ }^{10}$ However, the negated beliefs are logically quite difficult to deal with because there are two different reasons that $\neg \mathrm{B}_{\mathrm{i}} \phi$ could be true. It might be that $\mathrm{B}_{\mathrm{i}} \neg \phi$, and then from Rule 2 it follows that $\neg \mathrm{B}_{\mathrm{i}} \phi$; or it might be because the agent $i$ has no beliefs about $\phi$ at all, neither $\mathrm{B}_{\mathrm{i}} \phi$ nor $\left.\mathrm{B}_{\mathrm{i}}\right\urcorner \phi$, and from these facts it follows that $\neg \mathrm{B}_{\mathrm{i}} \phi$ by Rules 2 and 6 . In other words, an agent does not believe $\phi$ if it believes $\neg \phi$ or if it has no beliefs about $\phi$ at all.

We will not embark on a full-scale investigation of the negative FFs that are allowed by our grammar, but we will just make some preliminary remarks. To start with, each of the 10 FFs that we presented in Section 3.2 has an FF just like it but with an initial $\neg$. Recall that we showed in that section that formula 8 was equivalent to formula 4 , and 9 equivalent to 6 . Their negations are also equivalent: $\neg(8)$ is equivalent to $\neg(4)$, and $\neg(9)$ to $\neg(6)$. We also showed there that the embedded formula of (10) was a tautology and so requiring that $i$ believe it was not a real restriction. In the present case, the embedded formula of $\neg(10)$ is a contradiction, so it is impossible for $i$ to believe it, and so this is an impossible restriction. Thus, as in the positive case, we are left with the FFs $\neg(1)-\neg(7)$.

But here the analysis diverges from the positive case. Since (3) implied (6) and (7), we now have that $\neg(6)$ implies $\neg(3)$, and $\neg(7)$ implies $\neg(3)$. But $\neg(3)$ does not imply the conjunction of $\neg(6)$ and $\neg(7)$, but rather their disjunction, and so the analysis given for the positive case cannot be adapted to the negative one. Similarly $\neg(5)$ implies $\neg(4)$ and $\neg\left(7^{*}\right)$ implies $\neg(4)$, but $\neg(4)$ does not imply their conjunction.

A thorough analysis of the negative FFs is beyond the scope of this short paper, but it should be noted that there will now be many more FP-sets when we allow the negations to merge with the positives. (But a further thing to note is that no FP-set can have both

10 The model that seems to be employed by implementations of these BDI theories is that an agent maintains a database of its beliefs, and scans through it on an as-needed basis to determine whether or not some belief is in it. If it fails to find the desired belief $\phi$, it then adds $\neg \mathrm{B}_{\mathrm{i}} \phi$ to its belief-database, thus implementing Rule 5 . 
the positive FF and the corresponding negative FF. Furthermore, there are a number of other illicit combinations, such as no FP-set can contain both (3) and $\neg(6)$, or both (3) and $\neg(7)$... and so on.)

\section{What Speech Acts Could There Be?}

\subsection{The Speech Acts Generated by Our Method}

We look only at the positive FFs, and we start with Option A, to see what sort of speech act is correlated with each of the FP-sets. FP-sets 1(A) and 2(A) do not correspond to any speech act. This is because the mere belief of a proposition (or its negation) cannot by itself define a speech act in the absence of any other beliefs on the speaker's part. For, if it did, then corresponding to every belief one had there would be a speech act; and this subdivides the notion of speech act too finely. It would, for instance, not allow an agent to remain silent if it believes something (or else, it would define the silence as a type of speech act). FP-sets 3(A) and 4(A) also cannot generate a speech act, since they say only that the speaker believes that the hearer believes something. Without any further facts about the speaker's other beliefs this can't be enough to generate any particular speech act. If in addition to 3(A) the speaker did not believe $p$ (for example) then these together might generate a type of disagreement, whereas if the speaker did believe $p$ then together they might generate a confirmation of some type. But by itself 3(A) cannot determine any particular speech act.

The more interesting speech acts involve more FFs. FP-sets 5(A) and 8(A) are those cases where the speaker believes something and believes that the hearer believes it too. These both might be called "agree with", noting their difference from FIPA's 'confirm' that we gave in Section 2 (which required the speaker to believe that the hearer is uncertain about the proposition that the speaker believes). ${ }^{11}$ The FP-sets 6(A) and 7(A) are those cases where the speaker believes that the hearer believes the opposite of what the speaker believes. These are the preconditions for the speech act of "disagree with", which is different from FIPA's 'disconfirm' that requires the speaker to believe that the hearer is uncertain about the negation of the proposition that the speaker believes.

Option B gives us a somewhat different set of speech acts. Similarly to Option A, FPsets 1(B) and 2(B) do not give the speaking agent enough "mental life" to form a speech act. The mere fact that the agent does not believe that the hearer believes a proposition just cannot be enough content by itself to generate a speech act. FP-sets 3(B) and 6(B) have the hearer believe a proposition but not believe that the hearer does (recall that this "not believe" leaves open the possibility that the speaker thinks the hearer has no opinion about the proposition). This forms the preconditions necessary for what we might call

${ }^{11}$ It is also different from FIPA's agree, which is a commitment on the part of the speaker agent to perform some future action. We discuss some implications of these differences in $\$ 4.2$. 
"convince". FP-sets 4(B) and 5(B) are similar: the speaker believes a proposition but doesn't believe that the hearer believes the opposite. (Once again, it may be that the speaker thinks the hearer has no opinion on this opposite). Again, a possible name for the relevant speech act is "convince". But as in Option A, this is different from FIPA's 'disconfirm' and 'confirm'.

The remainder of the $\mathrm{FP}(\mathrm{B})$-sets can be restated in terms of the $\mathrm{Bif}_{\mathrm{h}}$-operator. Recall that $\operatorname{Bif}_{h}(p)=\left(B_{h} p \vee B_{h} \neg p\right)$, and hence that $\left.\neg \operatorname{Bif}_{h}(p)=\left(\neg B_{h} p \& \neg B_{h}\right\urcorner p\right)$. Further note that $\left(\operatorname{Bif}_{h}(p) \&\right.$ $\left.\neg B_{h} p\right)$ implies $\left.B_{h}\right\urcorner p$, while $\left(\right.$ Bif $\left._{h}(p) \& \neg B_{h} \neg p\right)$ implies $B_{h} p$. Using these facts we have

$$
\begin{array}{lll}
\text { 7(B): }\left\{\mathrm{B}_{\mathrm{i}} \neg \mathrm{Bif}_{\mathrm{h}}(\mathrm{p})\right\} & 10(\mathrm{~B}):\left\{\mathrm{B}_{\mathrm{i}} \mathrm{p}, \mathrm{B}_{\mathrm{i}} \neg \mathrm{Bif}_{\mathrm{h}}(\mathrm{p})\right\} & \text { 13(B): } \left.\left.\left\{\mathrm{B}_{\mathrm{i}}\right\urcorner \mathrm{p}, \mathrm{B}_{\mathrm{i}}\right\urcorner \mathrm{Bif}_{\mathrm{h}}(\mathrm{p})\right\} \\
\text { 8(B): }\left\{\mathrm{B}_{\mathrm{i}} \mathrm{B}_{\mathrm{h}} \neg \mathrm{p}\right\} & \left.11(\mathrm{~B}):\left\{\mathrm{B}_{\mathrm{i}} \mathrm{p}, \mathrm{B}_{\mathrm{i}} \mathrm{B}_{\mathrm{h}}\right\urcorner \mathrm{p}\right\} & \left.\left.14(\mathrm{~B}):\left\{\mathrm{B}_{\mathrm{i}}\right\urcorner \mathrm{p}, \mathrm{B}_{\mathrm{i}} \mathrm{B}_{\mathrm{h}}\right\urcorner \mathrm{p}\right\} \\
\text { 9(B): }\left\{\mathrm{B}_{\mathrm{i}} \mathrm{B}_{\mathrm{h}} \mathrm{p}\right\} & 12(\mathrm{~B}):\left\{\mathrm{B}_{\mathrm{i}} \mathrm{p}, \mathrm{B}_{\mathrm{i}} \mathrm{B}_{\mathrm{h}} \mathrm{p}\right\} & 15(\mathrm{~B}):\left\{\mathrm{B}_{\mathrm{i}} \neg \mathrm{p}, \mathrm{B}_{\mathrm{i}} \mathrm{B}_{\mathrm{h}} \mathrm{p}\right\}
\end{array}
$$

It seems pretty clear that in FP-sets 7(B), 8(B), and 9(B) there can be no speech act that has just that precondition, for the speaker $i$ is assumed to have no belief of its own, merely beliefs about the hearer. (Although perhaps they could be part of a complex speech act, such as a "request the hearer to inform the speaker", but such complex acts are a further step than is considered in this paper).

The more interesting cases occur when the speaker has some direct belief about the proposition $p$ and also has a belief about the hearer's beliefs. FP-sets 10(B) and 13(B) make the speaker believe a proposition $p$ but believe that the hearer has no direct beliefs about it. These are the preconditions for FIPA's "inform".

In FP-sets 12(B) and 14(B), the speaker believes some proposition and also believes the hearer shares this belief. This can be seen as forming the preconditions for the "agrees with" speech act we discussed in Option A. In FP-sets 11(B) and 15(B), the speaker believes the hearer has the opposite belief. And this would be the preconditions for the "disagree with" speech act. Again, though, it should be emphasized that these are different speech acts than FIPA's confirm and disconfirm.

So some of our FP sets are correlated with certain natural speech acts, namely

\section{FP-sets}

Option A: FP-5(A) and FP-8(A):

FP-6(A) and FP-7(A):

Option B: FP-3(B), FP-4(B), FP-5(B) and FP-6(B)

FP-10(B) and FP-13(B)

FP-12(B) and FP-14(B)

FP-11(B) and FP-15(B)
Corresponding Speech Act

agree with

disagree with

convince

inform

agree with

disagree with

(Categorizing FP-5(A) and FP-8(A), for instance, as being in one group reflects the fact that the two FP-sets are identical except for their propositional content. FP-5(A) has $p$ as its content while FP-8(A) has $\neg p$; and the same is true, mutatis mutandis, for all the other groups. We have already agreed that we were not going to individuate speech acts by 
their propositional content but only by the structure of their FP's; and this is why different FP-sets can correspond to the same speech act.)

\subsection{The Speech Acts in FIPA}

This method generates possible primitive speech acts that are not quite the same as FIPA's. For example, our agree with differs from FIPA's confirm and our disagree with differs from FIPA's disconfirm. And these differences are due to the same underlying feature: that FIPA has another modal operator that is not definable in our framework: $U_{i} \phi$, which means that $i$ is uncertain about $\phi$ but thinks it more likely than $\neg \phi$. Confirm $(i, \phi)$ requires that $i$ not only believe $\phi$ but also believe that the hearer is uncertain about $\phi$ (thinking it more likely than $\neg \phi$ ). Disconfirm $(i, \phi)$ requires that $i$ disbelieve $\phi$ but think that the hearer either believes $\phi$ or is uncertain about $\phi$. But our agree-with $(i, \phi)$ and disagree-with $(i, \phi)$ do not incorporate any notion of uncertainty.

It is important to note that our method could be used with an expanded language by adding the modal operator $\mathrm{U}_{\mathrm{i}}$ to our $\mathrm{SL}$ and then adjusting our grammar so as to include this operator, possibly along with the others. And in doing this we would generate some FP-sets that give rise to FIPA's confirm and disconfirm speech acts. As well, we would no doubt generate many other types of speech acts that are not recognized by FIPA. But this would be a longer excursion than we can undertake in this paper.

We also did not allow the speaking agent to have a $\mathrm{Bif}_{\mathrm{i}}$ attitude in general, but only in certain cases. Once again, we could alter the grammar so that the speaker itself could be the agent of a Bif. But this excursion is also to be saved for future work.

\section{What Have We Shown?}

We have given a kind of brute force method by which one can give a complete characterization of the communicative message types, or speech acts, in terms of their feasibility conditions. These feasibility conditions are themselves stated in a semantic language, and in our preliminary investigation we applied our method only to a very basic version of the semantic language - although we also indicated how it could be extended to more expressive languages. It remains to be seen whether the addition of further operators, e.g., $U_{i}$, or further types of legitimate FFs, will make this method become unwieldy. (If $U_{i}$ is to be added to the language, as FIPA clearly wants, then some serious study of a semantics for $\mathrm{U}_{\mathrm{i}}$ needs to be given before any analysis that involves our "modal reductions" can be undertaken, as we indicate in fn. 1 . For, although we could easily add $U_{i}$ to our grammars and mechanically produce a set of FFs with $U_{i}$, we would not be able to use our "semantic culling method" to reduce the sets.) With a very restricted grammar and assumptions about the content of an agent's mental state, we have shown that the space of possible combinations of beliefs is immense and that it is the KD45 semantics which reduces that dramatically. This is closely related to the conformance-verifiability problem [15]. 
Understanding the space of FPs is important, because FIPA assumes that an agent designer will use FIPA's core primitives, and that any newly-defined primitives will not semantically conflict with that core. We have shown that one of FIPA's four primitive acts is described by our method even in our impoverished semantic language. If the underlying semantic language were expanded so as to include some of FIPA's other operators (such as $U$ ), it seems clear that further omitted possible primitive speech acts would be uncovered. Our investigation has also described certain possible primitive communicative acts that are omitted from FIPA's list of primitive communicative acts: agree-with, disagree-with, and convince. We haven't argued that these message types should be added to the FIPA library, although we do not know of any reason why FIPA has omitted them. The issue of deciding on a core set of primitive message types has been a matter of debate ever since the notion of speech act was first introduced and subsequently adopted for agent communication. Our method gives a clear grip on how to investigate this topic.

\section{References}

[1] Austin, J.: How to do Things with Words. Harvard University Press (1962)

[2] Bach, K., Harnish, R.: Linguistic Communication and Speech Acts. MIT Press (1979)

[3] Breiter, P., Sadek, A Rational Agent as the Kernel of a Cooperative Spoken Dialogue System. In: Intelligent Agents III (LNAI Vol. 1193). Springer-Verlag (1997) 189-204

[4] Cohen, P., Levesque, H.: Communicative Actions for Artificial Agents. In: Proc. of the First International Conference on Multi-Agent Systems. AAAI Press (1995) 65-72

[5] Cohen, P., Perrault, R.: Elements of a Plan-Based Theory of Speech Acts. Cognitive Science 3 (1979) 177-212

[6] Cole, P., Morgan, J.: Syntax and Semantics, Vol. 3: Speech Acts. Academic Press (1975)

[7] FIPA: "Agent Communicative Act Library Specification" (2000 version) available at http://www.fipa.org/specs/fipa00037.

[8] Labrou, Y., Finin, T., Peng. Y.: Agent Communication Languages: The Current Landscape. IEEE Intelligent Systems, 14 (1999) 45-52

[9] Patil, R., Fikes, R, Patel-Schneider, P., McKay, D. Finin, T., Gruber, T., Neches, R.: The DARPA Knowledge Sharing Effort: Progress Report. In Rich, C., Swartout, W. Nebel, B. (eds.): Proc. Knowledge Representation and Reasoning (KR'92). Cambridge (1992) 777-788

[10] Sadek, M.: A Study in the Logic of Intention. In Rich, C., Swartout, W., Nebel, B. (eds.): Proc. Knowledge Representation and Reasoning (KR'92). Cambridge (1992) 462-473

[11] Sadock, J.: Toward a Linguistic Theory of Speech Acts. Academic Press (1975)

[12] Searle, J.: What is a Speech Act? In Black, M. (ed.): Philosophy in America. Cornell Univ. Press (1965) 221-239

[13] Searle, J.: Speech Acts. Cambridge University Press (1969)

[14] Singh, M.: A Semantics for Speech Acts. Annals of Math. and Art. Int. 8 (1993) 47-71

[15] Wooldridge, M.: Verifying that Agents Implement a Communication Language. In Proc. of $16^{\text {th }}$ Conference on Artificial Intelligence (AAAI-99). AAAI Press (1999) 52-57 